\title{
Mechanisms of technical ceramic density adjusting
}

\author{
Fedor Panteleyenko ${ }^{1,4^{*}}$, Andrzej Kuczumow ${ }^{2}$, Jan Sieniawski ${ }^{3}$, Katerina Panteleyenko ${ }^{1}$, \\ Valeri Shmuradko ${ }^{1}$ and Vladimir Korotin ${ }^{4}$ \\ ${ }^{1}$ Belarusian National Technical University, Minsk, Republic of Belarus \\ ${ }^{2}$ The John Paul II Catholic University of Lublin, Stalowa Wola, Poland \\ ${ }^{3}$ Rzeszów University of Technology, Rzeszów, Poland \\ ${ }^{4}$ T.F. Gorbachev Kuzbass State Technical University, 650000 Kemerovo, 28 Vesennyaya st., Russian \\ Federation
}

\begin{abstract}
In this paper authors overviewed the most important stages of ceramics production process which give significant influence on final properties of product. Often density and porosity on the all producing stages determines exploitation ceramics properties. A calculation method for fractions ratio selection which provides optimal density is suggested here. Also, density changes during operations of grinding, forming, thermal treatment and sintering a row of specimens are researched and analysed. The data received allow to predict semi products size behaviour while producing and get definite final part with dimension required.
\end{abstract}

\section{Introduction}

Comparative analysis of main contemporary constructive materials the man uses during all humanity history allows to make a conclusion that since $1950^{\text {th }}$ percentage of polymeric and ceramic materials increased greatly. Due to this changes nowadays ceramics amount in constructive materials equals metals' and polymers' rate and is about one third of all materials used $[1,2]$. It can be explained first of all by unique ceramics properties combination (high hardness and wear resistance, resistance to aggressive environments, thermal resistance and stability, etc.), which is determinative in conditions of rapid development of the scientific and technical complex. Progress leads to working conditions tightening (working temperatures and loads value increasing) especially for machine parts, constructions and tools in aerospace, metallurgy and other spheres [3].

Wide range of study in the field of functional oxide ceramics producing area shows that every stage of technological process is very significant for final required properties getting [3-8]. Meanwhile there are three of the most important stages distinguished: choose of chemical composition, granular composition and thermal sintering cycle.

In general $\mathrm{Al}_{2} \mathrm{O}_{3}$ as a basic material for oxide ceramics is used. Widely used additives are: $\mathrm{MgO}, \mathrm{ZrO}_{2}, \mathrm{CaO}, \mathrm{SiO}_{2}[3,4]$. Properties forecasting begins just at the stage of chemical composition choose and state diagram analysis [6,7]. Ratio of components can determine

\footnotetext{
*Corresponding author: panteleyenko@inbox.ru
} 
the features of the subsequent technical process, especially sintering process [8]. The last one influence on phase crystal lattice and phase composition and exploitation properties of product [9].

Grinding of the oxide mixture chosen leads to so-called activation of it. Especially important point is to get nano-sized particles with a lot of structure defects. Last ones play considerable role in sintering process as a source of vacancies during vacancy diffusion mechanism effect [9]. Moreover, particles size influence on features of the compaction process during pressing and density of the product.

Thermal sintering cycle complexity and sintering temperature value usually are settled on the assumption of previous two factors. Especially important is the initial chemical components ratio, which determines sintering temperature on state diagram base. It should be noted that multicomponent state diagram much more complicated than for two elements.

\section{Mechanisms, which flow during ceramics pressing and sintering}

Process of molding ceramics (pressing) includes mechanisms of particle redistribution inside of mold, elastic and plastic deformation. For ceramic compositions elastic deformation is practically the only one. The range of pressing load optimal value for such systems is in limits $50-250 \mathrm{MPa}$.

During compaction the mechanisms of particles and liquid displacement occur. Initially liquid contains in in wetting films, capillaries and pores. While compressing, volume of powder material reduces and relative percentage of liquid increase.

Gas phase (air) under the pressure partly forced out of the pressing, the rest one, compressed in pores, redistributes in volume of molding and dissolve in liquid binder. The air pressure inside increases significantly

The factors, which result in negative way, are the next: large size of powder particles (complicate the process of forming a compact homogeneous prepack); extremely high pressure (up to $100 \mathrm{~atm}$.) of air inside the compact. Too small particles size is also unwanted due to maximal elastic expansion after load relief. [10].

During sintering process there are four stages: interparticle baking with borders keeping; local interparticle agglomeration with borders vanishing and open channel porosity forming (phase of matter and phase of void); closed pores appearance; closed pores removal. Phase equilibrium state diagrams allow recognizing phases existing at different temperatures, building fluid curves, defining minimal eutectic temperature and correct determining of temperature stages of sintering, new phases forming and mass transfer mechanisms existing[11].

In corundum- and corundum mullite based powder systems the diffusion is carried out via next mechanisms:

1)Surface diffusion mechanism $\left(800-1200^{\circ} \mathrm{C}\right)$;

2)viscous flow mechanism $\left(1000-1500^{\circ} \mathrm{C}\right)$;

3)volume diffusion mechanism $\left(1200-1800{ }^{\circ} \mathrm{C}\right)$;

4)evaporation-condensation mechanism (temperature depends on the chemical and phase compositions);

5)dislocation mechanism $\left(1200-1800^{\circ} \mathrm{C}\right)$.

Besides, for aluminosilicate, corundum mullite and zirconia compositions non-shrinking sintering carries in different temperature limits: $800-950^{\circ} \mathrm{C}, 900-1100^{\circ} \mathrm{C}$ и $900-$ $1200^{\circ} \mathrm{C}$ respectively. So, it's almost impossible to demarcate conditions of definite diffusion mechanism running in complex systems. As far as several mechanisms could run simultaneously, it's rather complicated to conduct mathematical modeling of ongoing processes. 
For a more thorough study of the ceramic products properties predicting possibilities in this work, a fractional composition calculation method was proposed. It allows selecting the optimal size ratio of the initial mixture components from the point of minimal pressing loads and maximal density of compact products. Also an experimental study of the density changes in corundum and corundum mullite compositions $\left(\alpha-\mathrm{Al} 2 \mathrm{O} 3, \mathrm{Al}_{2} \mathrm{O}_{3}+3 \mathrm{Al}_{2} \mathrm{O}_{3} \cdot 2 \mathrm{SiO}_{2}\right)$ on the stages of filling, vibration shake, pressing and sintering in correlation with fraction composition of powders.

\section{Fractions compositions optimization of oxide ceramic and their influence on forming and sintering processes}

It is prooved, that packing dencity of systems close to monofraction and consisting mainly of isometric grains of irregular shape, practically does not differ from stacking balls. In powder systems which consist of several fractions significant increase in packing density is possible [11].

On the fig.1 graphs for fractional composition relation selection for the most dense packaging (by Andreasen [12]) is shown. This calculation method for fractions ratio selection was realized using software Mathcad and can be implemented for heterogeneous fractional composition: fine fraction $10-100 \mathrm{mkm}+$ coarse fraction $500-3000 \mathrm{mkm}$ (fig.1,a) ; fine fraction 0,05-10 mkm + coarse fraction 100-1000 mkm (fig.1,b).

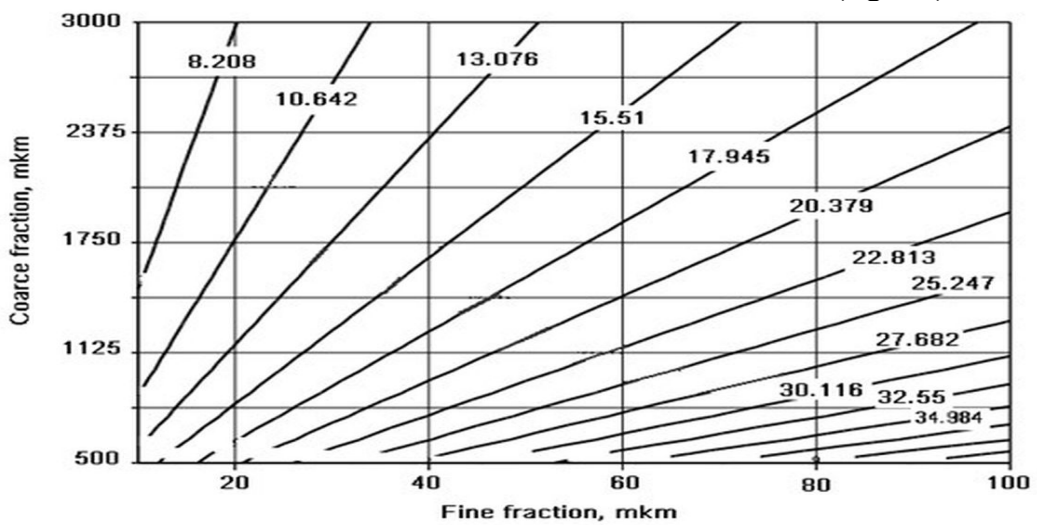

a)

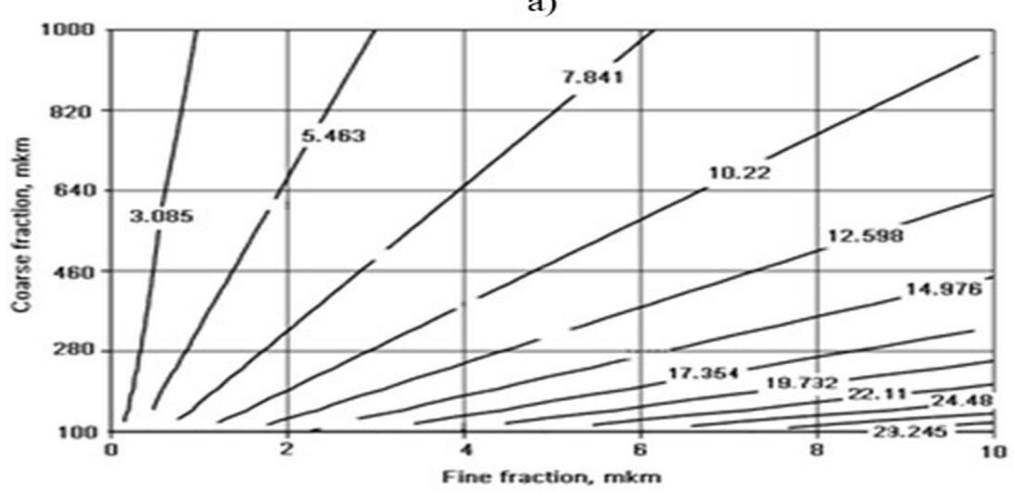

b)

Fig.1. Calculation method for fractions ratio selection: a - fine fraction 10-100 $\mathrm{mkm}+$ coarse fraction 500-3000 mkm; b - fine fraction 0.05-10 mkm + coarse fraction 100-1000 mkm 
Isolines of graphs determine percentage of fine fraction inputed in dependence on the amount of coarse fraction. These dependencies allow to choose the optimal ratio of fractions of the components of the initial systems. That choice result in dense packing of powder particles during all following stages of technology: vibroforming, slip and thermoplastic molding, pressing and subsequent sintering.

It should mind that with a difference in the fractional compositions of the initial component powders, the sintering time is determined considering the size of coarse particles. After analysis of sintering time for different fractions of powders the next equality can be formulated:

$$
\tau_{2}=K^{\gamma} \cdot \tau_{1}
$$

where $\tau_{2}$ - sintering time for particles with semidiameter $\mathrm{R}_{2}, \tau_{1}$ - sintering time for particles with semidiameter $R_{1}, K^{\gamma}$ - coefficient, $K^{\gamma}=R_{2} / R_{1}$.

This equality is also known as the dimensions law. Exponent $\gamma$ depends on the sintering mechanisms : during viscous flow $\gamma=1$; during evaporation-condensation mechanism $\gamma=$ 2 ; when sintering by the mechanism of volume diffusion $\gamma=3$; during surface diffusion $\gamma=4$ [12]. Dimensions law is implemented for main sintering mechanism determination. It is used for isotropic powders with particle size $0.01-1 \mathrm{~mm}$.

For research of processes and mechanisms which carry out on the stages of corundum and mullite-corundum systems structuring while grinding, forming, thermal treatment and sintering a row of specimens was received.

Specimens were made of corundum of five grading, pressed under 100MPa load and sintered at temperature $1700^{\circ} \mathrm{C}$ during 1 hour. Their compositions are the next:

$1-$ corundum M14 (particle size $/$ diameter $=14 \mathrm{mkm})-75 \%+\mathrm{M} 1-25 \%$ (particle size $/$ diameter $=1 \mathrm{mkm})$;

$2-$ corundum M20 (particle size $/$ diameter $=20 \mathrm{mkm})-77 \%+\mathrm{M} 1-23 \%$ (particle size $/$ diameter $=1 \mathrm{mkm})$;

$3-$ corundum M63 (particle size $/$ diameter $=63 \mathrm{mkm})-75 \%+\mathrm{M} 1-25 \%$ (particle size $/$ diameter $=1 \mathrm{mkm})$;

$4-$ corundum M180 (particle size $/$ diameter $=180 \mathrm{mkm})-67 \%+\mathrm{M} 1-33 \%($ particle size $/$ diameter $=1 \mathrm{mkm})$;

5 - corundum M400 (particle size $/$ diameter $=350-400 \mathrm{mkm})-67 \%+\mathrm{M} 1-33 \%$ (particle size $/$ diameter $=1 \mathrm{mkm})$.

Grinding was carried out in attritor during 1 hour; before pressing of the powder mixture a binder on the base of polyvinyl alcohol solution (PAS 7-8\%) was added to. To evaluate density changes of semi products during technological process a row of graphs was built. On the fig.2-5 the density characteristics in dependence on main particles size of powder compositions are given.

As it is seen on fig.2, in general backfill density directly proportional to the main particle size, but dependence is non-linear. The dependences received show, that PAS addition decrease backfill density and shake density. But one should admit that PAS allows getting more dense and strong semi product after pressing due to influence on particles redistribution processes. Moreover, possibility of semi products' cracking and destroying while transporting between technological operations decreases significantly. Therefore, all subsequent dependencies (fig.3-5) are for the semi products with PAS addition. 

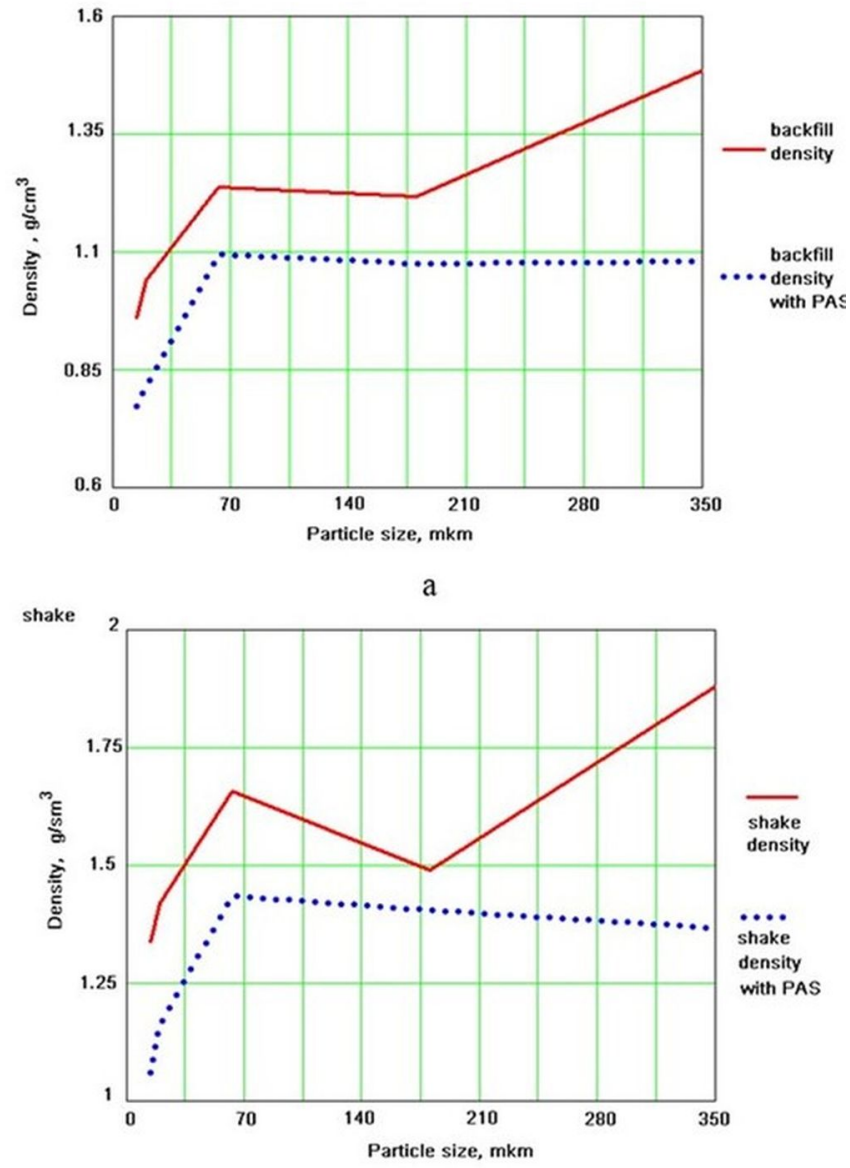

b

Fig.2. Dependence of backfill (a) and shake (b) density (g/sm3) of compositions with and without PAS on the main particle size $(\mathrm{mkm})$

Curves on the fig. 3 establish non-linear dependence density of raw and sintered semi products on particle size. The greatest density change is for semi products made of compositions with minimal grain size (less than $25 \mathrm{mkm}$ ). 


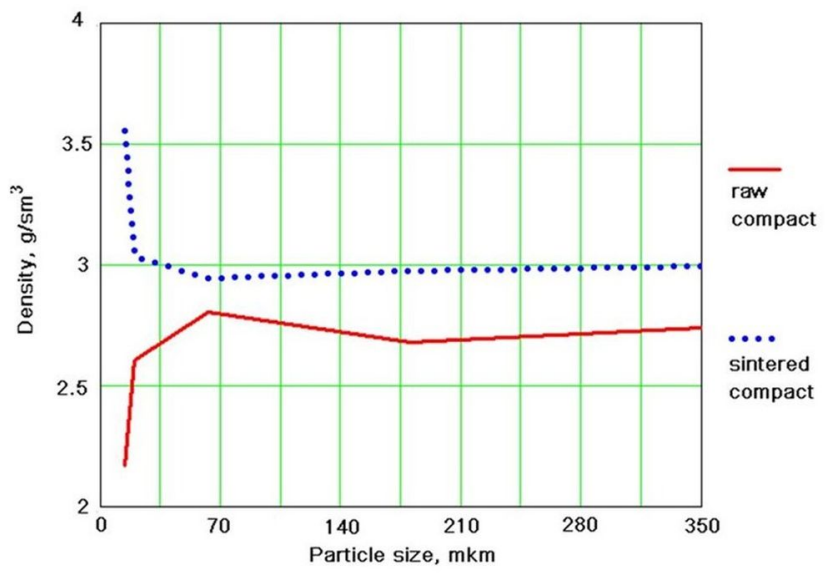

Fig. 3. Raw (after pressing) and sintered compacts' density (g/sm3) dependence on main particle size $(\mathrm{mkm})$

To build a graph on fig.4 the next formulas were used:

- internal diameter shrinkage $-\Delta d=100 \cdot\left(\mathrm{d}_{\text {raw }}-\mathrm{d}_{\text {sintered }}\right) / \mathrm{d}_{\text {raw }}, \%$;

- external diameter shrinkage $-\Delta \mathrm{D}=100 \cdot\left(\mathrm{D}_{\text {raw }}-\mathrm{D}_{\text {sintered }}\right) / \mathrm{D}_{\text {raw }}, \%$;

- height shrinkage $-\Delta \mathrm{h}=100 \cdot\left(\mathrm{h}_{\text {raw }}-\mathrm{h}_{\text {sintered }}\right) / \mathrm{h}_{\text {raw }}, \%$.

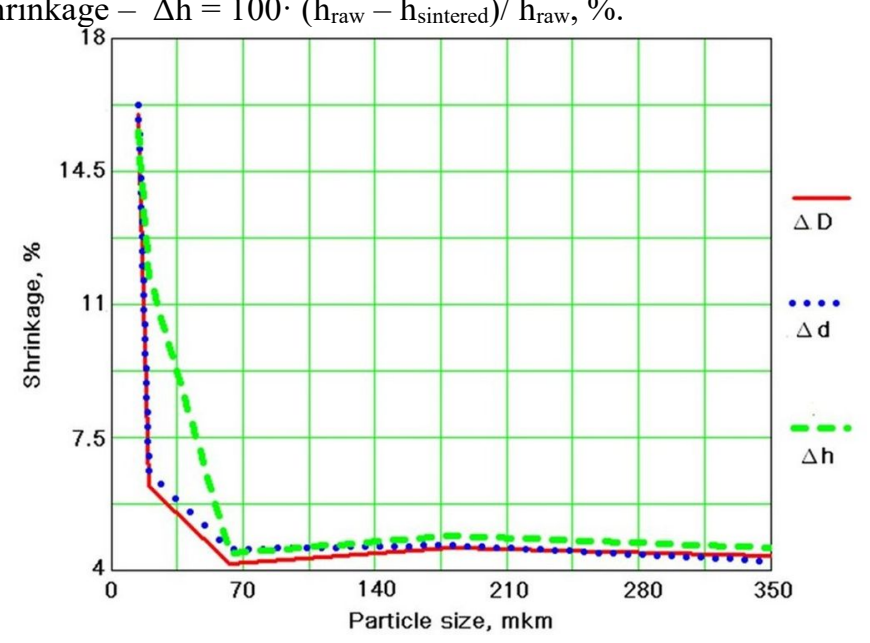

Fig. 4. Dependence shrinkage (\%) of external diameter (D), internal diameter (d) and height (h) of specimens after sintering on main particle size

For the next graph authors used next formulas: compactibility $\Delta \rho=\left(\rho_{\text {raw }}-\rho_{\text {sintered }}\right) / \rho_{\text {raw }}$; weight increase $\Delta \mathrm{m}=100 \cdot\left(\mathrm{m}_{\text {raw }}-\mathrm{m}_{\text {sintered }}\right) / \mathrm{m}_{\text {raw }}, \%$. 


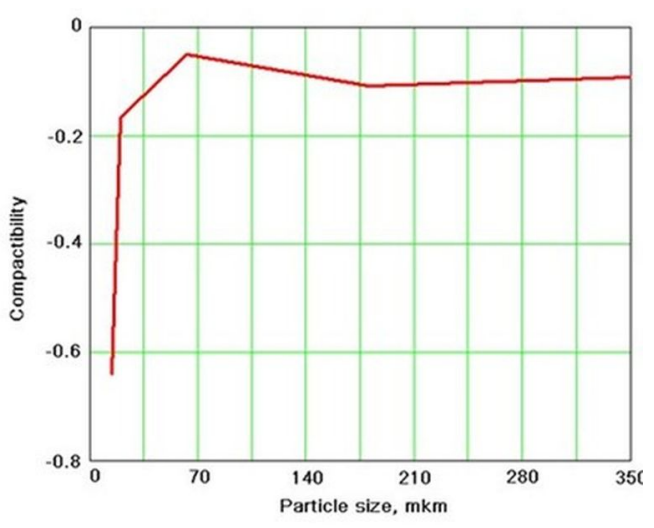

a

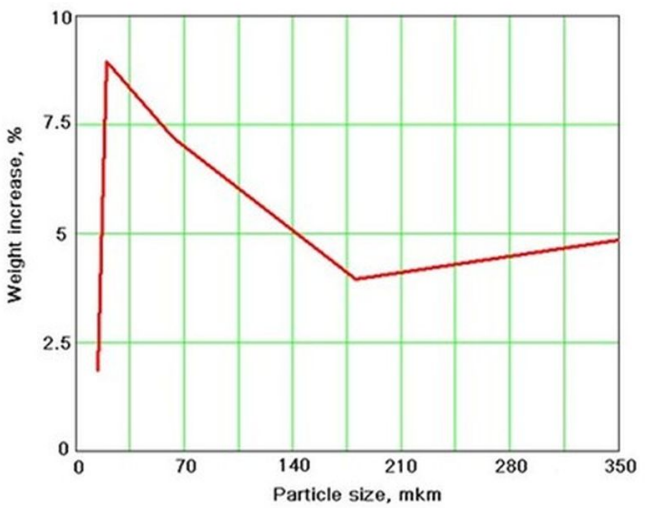

b

Fig. 5. Compactibility (a) and mass decrease (b) dependences on main particle size (mkm) of sintered specimens in comparison with raw pressed ones

All dependences show abnormal conduct in area of rather small particle size - up to 70 mkm. So, compacts made of such compositions have maximal changes in density, porosity, dimensions and mass when pressing and sintering. That's why one should take into consideration this information at stages of tools design and manufacturing for oxide ceramics production. Also, there is a need to more deep investigation of changes and behaviour for system with main grain size less $70 \mathrm{mkm}$.

\section{Conclusions}

The investigations carried out in issues of fine and coarse fractions ratio adjusting for ceramics composition mixtures and density and dimensions changes during different technology stages allow to:

- choose optimal ratio of components for maximal density providing;

- exclude cracking and geometry changes while transporting and sintering of semi products, especially of thin-walled ones ;

- to forecast the final sizes of sintered ceramic parts in order to minimize finishing cutting treatment (grinding). 
The data described used for tools size computations and technological process development while producing disk (fig.6,a) and support (fig.6,b) rollers for steel wire and cord production [13-15].

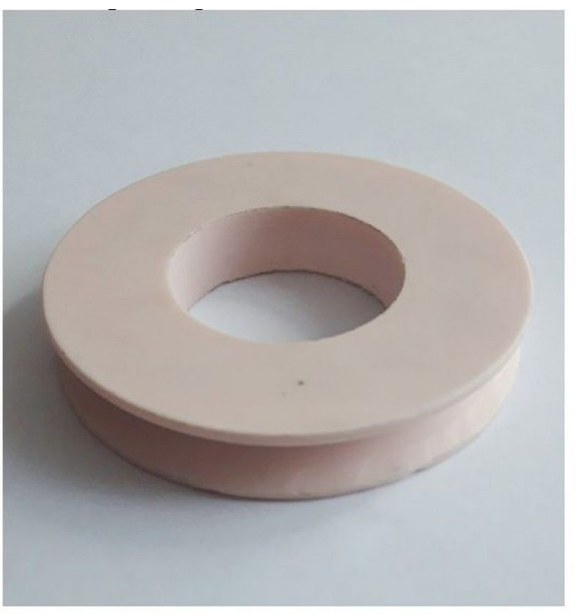

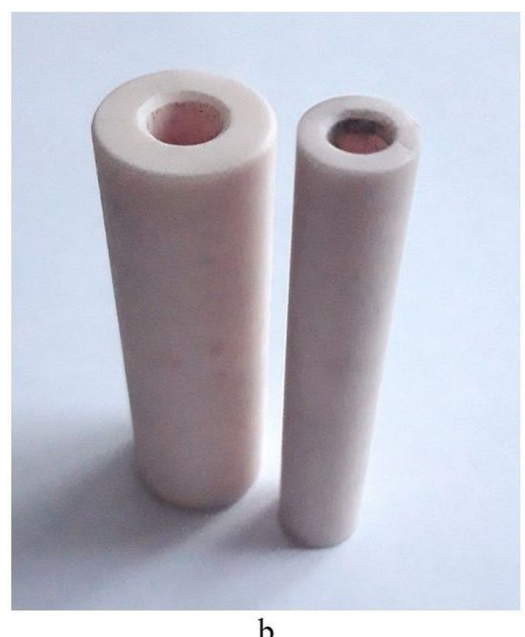

Fig. 6. Corundum disk (a) and supporting (b) rollers for steel wire and cord production

These products have passed industrial tests at Byelorussian steel works successfully.

\section{References}

1. M. Ashby, K. Johnson. Materials and design. The art and science of materials selection in product design (Amsterdam - Boston - Heidelberg - London - New York - Oxford - Paris - San-Diego - San-Francisco - Singapore - Sidney - Tokyo, 2003)

2. Leszek A.Dobranski. Metal engineering materials (Wydawnictwo NaukowoTechniczne. Warsaw, 2004)

3. S.V. Matryonin, A.I. Slosman. Technical ceramics (Publishing office TPU, Tomsk, 2004).

4. K. Nozaki, M. Kawaguchi, K. Sato, M. Kuwabara. J. Mater. Sci.,30, 3395 (1995).

5. P.P. Budnikov, D.N. Polubojarinov. Chemical technology of ceramics and refractories (Moscow, 1972).

6. A.G. Khachaturian. Theory of phase transformations and the structure of solid solutions (Science, Moscow, 1974).

7. Galakhova F.Ya. State diagrams of refractory oxide systems (Science, Leningrad, 1985).

8. M.U. Balshin. Scientific basis of powder metallurgy and fiber metallurgy (Metallurgy, Moscow, 1972).

9. F.I. Panteleyenko, V.T. Shmuradko, O.P. Reut, N.A. Rudenskaya et.all. Glass and Ceramics, 9, 16 (2016).

10. Ya.I. Frenkel. Kinetic theory of fluids (Publishing house "Science" : Leningrad, 1975)

11. F. Lenel, Powder metallurgy, 6 (1964)

12. K.K. Strelov. Theoretical foundations of refractory technology (Metallurgy, Moscow, 1985).

13. F.I. Panteleyenko, V.T.Shmuradko, et.all. Patent of the Republic of Belarus № 21214 (2017) 
14. F.I. Panteleyenko, V.T. Shmuradko, O.P Reut, et.all. Refractories and industrial ceramics, 257, 6, 614 (2017).

15.F. Pantsialeyenka, A.Kuczumov, V.Shmuradko, K.Pantsialeyenka, WFC, Krakow, Poland, 465 (2018). 